\begin{tabular}{l|l|l|l|l}
\hline Volume 1 & Issue 3 & December (2020) & DOI: 10.47540/ijsei.v1i3.112 & Page: $182-190$ \\
\hline
\end{tabular}

\title{
Ogo: A Cultural System Moves and Damage of the Environment
}

\author{
Zainur Wula ${ }^{1}$, Hadjrah Arifin ${ }^{2}$ \\ ${ }^{1,2}$ Universitas Muhammadiyah Kupang, Indonesia
}

Corresponding Author: Zainur Wula; Email: wulazainur@gmail.com

\begin{tabular}{ll}
\hline A R T I C L E I N F O & A B S T R A C T \\
Keywords: Cultural Systems; & $\begin{array}{l}\text { Humans and the natural environment have a very close relationship; it can even be } \\
\text { Environmental Damage; Ogo; Shifting } \\
\text { called interdependence. Humans have a very high dependence on fulfilling the } \\
\text { necessities of life, the most important of which are clothing, food, and shelter which } \\
\text { have the main source of raw materials from the natural environment, especially in } \\
\text { communities whose farmers depend on the natural environment and land. The }\end{array}$ \\
$\begin{array}{l}\text { Received : }: 23 \text { November } 2020 \\
\text { Revised }: 01 \text { December } 2020\end{array} \quad \begin{array}{l}\text { culture of people's lives in the shifting cultivation system called ogo is one of the } \\
\text { Accepted }: 05 \text { December } 2020\end{array}$ & $\begin{array}{l}\text { main factors in forest and environmental damage in a broad sense because forests } \\
\text { are not only related to grass and timber trees but also land, rocks, water, fauna. The } \\
\text { research method used is qualitative with a case study approach. The data were } \\
\text { collected through documents, in-depth interviews, and observations, and data } \\
\text { analysis was carried out descriptively. The results showed that forest and } \\
\text { environmental damage due to excessive use with the ogo culture of shifting } \\
\text { cultivation with a period of three to four years resulted in reduced water reserves } \\
\text { due to damage to water infiltration, floods, and landslides as well as damage to } \\
\text { residential areas. Roads and bridges in the village of Nuanaga in February } 2016 . \\
\text { Ogo as a socio-cultural system of shifting cultivation is an act of rational choice by } \\
\text { farmers in increasing income and the dignity of family life, despite frequent floods } \\
\text { and landslides in the rainy season with high intensity. }\end{array}$ \\
\hline
\end{tabular}

\section{INTRODUCTION}

Nature and the environment are an important part of the ecosystem which functions as the main support for the life of all living things on the earth's surface directed towards the realization of environmental sustainability. The function of environmental preservation is intended to create a dynamic balance and harmony with population development so that in the end it can guarantee the survival of the plant, animal, human beings and is specifically able to provide resources to meet the needs of the people in an area. Human and government attention in environmental development aims to improve environmental quality, utilize natural re-sources responsibly which is implemented through efforts to rehabilitate environmental damage, control pollution, and improve the quality of the environment itself. One important part of the environment is the forest. Forest is a vast expanse of nature in which there are various types of animals and plants. Forests function as a supplier of oxygen, a reservoir for carbon dioxide, prevention of natural disasters, as well as guardian of soil fertility, and many other forest functions, and in general Indonesia's forests have decreased very drastically over time.

Therefore a good and healthy environment is the basic right of every Indonesian citizen as mandated in Article $28 \mathrm{H}$ of the 1945 Constitution of the Republic of Indonesia and the implementation of national economic development as mandated by the 1945 Constitution of the Republic of Indonesia shall be carried out based on principles of sustainable and environmentally sound development.

In this connection, the environment is nature which includes the state of the land, water, trees, climate, flora, and fauna around the community's residents. Furthermore, in simple terms, the harmony and harmony of human interactive relationships with their natural environment can be understood from the existence of nature as a place of human life that provides resources for fulfilling basic human needs in the form of clothing, food, 
shelter, and social, meaning that nature becomes a source of human livelihood.

The interactive relationship and interdependence between the environment and human existence are called in Talcott Parson's system theory (in Poloma, 1997), which states that "the system is an inseparable linkage between the various components in a socio-cultural, political and economic system, if a component in a system is disturbed, there will be an imbalance that creates pathology". Likewise with the wider community. According to this theory, society consists of various elements or institutions. These elements include economy, politics, law, religion, education, family, culture, customs, natural resources, the environment, and others. Likewise with the wider community. According to this theory, society consists of various elements or institutions. These elements include economy, politics, law, religion, education, family, culture, customs, natural resources, the environment, and others.

Adherents of the functional approach see society and social institutions as a system in which all parts depend on each other and work together to create a balance (equilibrium). They do not reject the existence of conflict in society, but they do believe that society itself will develop mechanisms that can control conflicts that arise. This is the focus of analysis for functionalists. According to this theory, society is a social system consisting of parts or elements that are interrelated and are united in balance. Changes that occur in one part will also bring changes to other parts (Ritzer, 1992).

Nuanaga Village, which is located in Kota Baru Subdistrict, Ende Regency, is like other villages in Ende Regency whose daily life depends on the hope of the agricultural and plantation sectors which has an ogo culture, which is that every three to four years opens and expands its farms. Ogo's farming habits have been going on for hundreds of years since the time their ancestors occupied this residential area. In addition, hundreds of years ago, gardens and fields were also residential areas, which means that if in a certain time the land is no longer fertile or if the trees are tall, especially in the past, cashew nuts were not yet known, people planted candlenut trees, then they would moving to open $O g o$ as a new farm. Therefore, what is happening in the expansion of community agricultural land and deforestation which occurs due to the cutting down of lots of wood and large trees. Another impact that can be caused by ogo is that if there is heavy rain and it lasts a long time, floods and landslides can occur which cause material and life, and property hazards.

One of the causes of environmental damage is the behavioral and cultural factors of human life which in exploiting natural environmental resources are carried out excessively and irregularly, namely the system of agricultural patterns and shifting cultivation of fields. In the culture of the Lio people, the shifting cultivation system that utilizes the mountainous and sloping nature is called $O g o$. The system of shifting cultivation has been going on for hundreds of years until now. Irregular felling of forests and trees causes environmental damage, namely floods and landslides that destroy fields, crops, housing, and human settlements as well as property which occurred in February 2016 in the village of Nuanaga, Ende Regency.

$O g o$ as a basic conception of shifting cultivation by utilizing natural resources and the environment can also be seen from the perspective of rational choice theory. Rational choice theory is often seen as a theory that differs from other theoretical approaches in sociology in two ways, namely (1) its commitment to individualism methodology and (2) its view of choice as an optimization process. The individualism method used by sociologists includes rational choice theory to explain intentional (aiming) actions. This method is used in studies that focus on how individual actions aim not only to have the expected impact, but also those that have undesirable or unanticipated impacts. Marx Weber (1963) and Karl Popper (1971), are two sociologies who suggest using this method. They oppose any form of holistic explanation that refers to systemic or societal needs. Some sociologists who use this method aim to explain rational action. According to him, rational action is an intentional action accompanied by the assumption that people act rationally. People act rationally when they have a preference framework and make decisions according to that preference frame. In addition, individuals have rational beliefs about how to get what they want and about the costs and benefits that may be obtained. Rational choice theory (or rational action theory) offers a rational explanation. 
A second feature of rational choice that is often seen as distinct from traditional sociological theory is its view that choice is an optimization process. Choice is seen as something rational. It is important to note here that, unlike classical economics, contemporary sociology of rational choice theory does not assume that income or profits are maximized. Therefore; according to Heckarthorn (2005), rational choice theory moves from the classical microeconomic assumption that individuals seek to maximize income, towards an understanding of the multiplicity of egoistic and altruistic goals that can direct behavior. This is an analysis that Jane Mansbridge calls inclusive modeling, an analysis that in principle does not regard self-interest as the only motive. The selfinterest motive together with other motives will result in maximum and consistent decision-making. Rational choice theory falls into this category. More than that, contemporary rational choice theorists see rationality as being "bound", that is, decisionmakers are seen as having limited access to information and the ability to engage in information processing. Thus, rational choice theory also moves away from microeconomic assumptions about the complete information individuals have when making decisions (making choices). Because of this bound rationality, actors often cannot anticipate the effects of their actions. Some of the consequences of his actions may be undesirable.

Geographically, the village of Nuanaga is located under the valley of the Cobaleba mountains in the West and South, in the east by the Ndondo River which has a width of more than 100 meters and the northern part faces the Flores Sea. Kali Ndondo has a length of more than $20 \mathrm{KM}$, where water flows throughout the year and the demand for water from the people of Ndondo is also very dependent on the Ndondo River, which topographically the land conditions consist of mountains, valleys, and flat. With a fairly good level of soil fertility, in this area, there are coconut, cashew, and cacao trees, mangoes, bananas. The agricultural system is still subsistence, not marketoriented, with the main income being rice corn for its own consumption Whereas for plantation and trade crops as outlined above, namely coconut, cashew, chocolate, when it is time to harvest, the results are sold to buyers and other traders.

\section{MATERIALS AND METHODS}

Humans and the natural resource environment in the perspective of structural functionalism theory is seen as a social equilibrium of all social institutions in it, each institution/parts, elements, components of society contributes specific functional according to their respective patronized roles. for the sake of preserving a dynamic balance system. As the totality of the social system, society creates patterns of behavior consisting of norms that are considered legitimate and binding on its members, namely norms, both customs and legal norms that have interdependence with other parts, and changes in certain parts, components or elements can be influence on others (Parson, in Poloma, 1997).

This research was conducted in Nuanaga Village, Kota Baru District, Ende Regency, from March to May 2017. The research was designed descriptively with a case study approach (Allan, G. 1991) where data collection techniques were carried out through document review, observation, and indepth interviews. As for data collection activities through interviews with several informants and participatory observation as far as possible to accommodate all the opportunities for obtaining the required data. Techniques carried out by Snowball informants and researchers as key instruments (Bailey, Kenneth D., 1987).

Research subjects are all informants who will be interviewed who can provide information about certain characteristics of the research object, namely farmers who own ogo agricultural land, traditional leaders, community leaders, and village government. Because this research is a type of qualitative research and the resulting data is qualitative data, the results of this study will then be analyzed descriptively (Creswell, 1994). In addition, quantitative data is still needed to determine the level of tendency for environ-mental damage to occur. Its impact on the social life of the community in relation to housing and agricultural land and plantations.

\section{RESULTS AND DISCUSSION \\ Ogo cultural system of shifting cultivation and environmental damage}

Nuanaga Village, located in the Kota Baru Subdistrict, Ende Regency, has 179 households (KK) with a population of 1,253 . Of the population, 
$97 \%$ of the population work as farmers, while $3 \%$ of the population work as fishermen. As farmers, the people of Nuanaga village rely on jobs from the agricultural sector with $O g o$ gardening, which is a system of shifting cultivation for a certain time. The results showed that the ogo shifting cultivation system was carried out for 3 (three) to 4 (four) years, which means that every resident who has ogo survives in a place or location for about three to four years and a maximum of four years after that will seek and make a new ogo again.

The dynamics and changes in the people's mindset are a reality that continues to occur in life with a complex scope of individuals, communities to fulfill their needs by continuing to pay attention to and the realization of a balance between the interests of the community through social order in maintaining the quantity and quality of the natural resource environment. The very rapid social change in agriculture, especially land use, is influenced by many factors, including increasing birth rates, increasing population, increasing living needs, employment which has an impact on increasing the need for life due to excessive use of natural resources resulting in environmental damage and humanitarian disasters. One of the reasons is the shifting cultivation system which in the local culture of Nuanaga is called $O g o$.

The period for $O g o$ or the system of shifting cultivation is because for three to four years farmers have to take care of their cashew and candlenut plantations until they are three to four years old and then move places, which means that when they enter the following year, the cashews can produce and sold to meet the needs of family life, while the candlenut which is called a long life plant has a fruiting period or produces 8 to 10 years.

Living needs for natural resources from time to time are in line with population growth and development. The birth rate which continues to increase from time to time with the failure of family planning also contributes greatly to population growth without the control of the family planning program (KB). On the other hand, the availability of natural resources, especially forests, as the support for human life and the surrounding community is decreasing. This is of course caused by the culture of people's lives with a system of shifting cultivation called the $O g o$ culture.
Ogo farming can only last a maximum of 4 years because if it is more than three years it is believed by the community that the land is no longer fertile, besides that the fields are already filled with commercial crops and cashew and candlenut plantations. Meanwhile, within 5 to five years the plantation and trade crops can be harvested for cashew, while for candlenut it takes up to a quick period that takes at least 8 to 10 years and you can get results if the soil is really fertile. Meanwhile, for cashew, the harvest has been obtained for about 5 years.

Therefore, the community will look for and open new ogo to plant rice, maize, and other crops. By opening a new ogo, it means that many forests and large and small timber trees are cut down due to the expansion of the ogo area, not only forests and wood but also bamboo plants that are tens and hundreds of years old have also been damaged. This results in the availability of natural resources both in terms of quantity and quality to be reduced from time to time.

Based on the results of the study, almost ninety percent $(90 \%)$ of the expansion of ogo as a new cultivation area was carried out on mountainous area, valleys, and gorges, so that of course it had a very large impact on environmental damage, namely floods, landslides and springs decreases and even disappears and the other impact is an increase in the social burden of the community in realizing welfare.

Based on interviews with the village head, Nuanaga emphasized that around $97 \%$ of the community's livelihoods are farmers and their lives are very dependent on $O g o$. So ogo is an inseparable part of community life in this village to fulfill the necessities of life, namely for gardening or fields. Ogo in the local language and what is often referred to as the shifting cultivation system, because the community realizes and has life experience that if planting in the same place for a maximum of 3 years or 4 years the land is still fertile, the rest is no longer fertile, so to plant rice corn, tubers which are the primary necessities of life cannot be achieved. In addition to the infertile land, in the first year $O g o$ was not only planted with corn and other crops, but plantation crops, namely cashew and candlenut, so that when it arrived three or four years the plants had grown so that the land was no longer fertile, but it was profitable. the 
community is already owning a plantation. This habit has been going on since the time of their ancestors (interview with Agustinus Pana, Head of Nuanaga village, March 21, 2017).

Furthermore, from the interview the author with one of the farmers in Nuanaga emphasized that our choice to survive is farming and farming requires a business field, agricultural land, and plantations, while for rice fields we don't have it, therefore we choose ogo. For ogo, it is not new now and it has been going on for a very long time, with ogo we can also plant corn, tubers, and vegetables, pumpkin, cucumber, tomato, chili, papaya. Besides that, Ogo's advantage is that we can plant plantation crops including cashews and candlenuts. We can harvest these plants for cashew nuts for about 4 years and candlenut can be 8 years and over and the longer the candlenut trees can produce more. So if someone wants to forbid us, don't be ignorant, where do we want to live from, what do we want to eat (Interview with Adrianus R, dated, 21 March 2017).

In line with that, a Nuanaga community farmer emphasized that we, the people here (Nuanaga village) really rely on farming, if there is no cultivation or even if it is forbidden it means what we want to eat, our life is very dependent on the management of the fields so we can plant corn, rice and tubers and vegetables. Maybe in other villages or other areas that don't rely on farming because they have rice fields, moreover they have water and irrigation can plant and harvest up to two times a year, while we only rely on rain. Besides that, it was an opportunity for us to grow commercial crops such as cashew nuts and candlenuts. Indeed, in this area, there are many coconut trees, but coconuts are only planted in low or flat plains and if there are coconut trees, it means that they cannot grow, because rice and maize do not grow and develop if there are plants that are around them, let alone in the shade and coconut trees are very tall. . It means that if we plant under it we cannot produce anything, it is difficult for us to meet the needs of our family (Interview with Stefanus G, March 23, 2017).

The above matter was re-questioned by one of the traditional leaders of Nuanaga, who emphasized that: $O g o$ is part of the life of the farming community, part of the socio-cultural work system of farmers. With OGO we can survive, can meet the needs of our family, can send our children to school, can build houses, and so on, besides that, with OGO we can plant plantation crops, which one day when the plantation crops are big we can harvest to sell them, especially now that the price of cashew per coconut is very expensive as is the candlenut. This means that as long as there is no other way for the new job of the farmer so that there is no longer an ogo for us, it is very difficult, the suffering of the community continues to increase, while to switch to another job we cannot, do not have skills and low human resources, do not finish elementary school. What skills do you want? Yes, for us, this is the work inherited from our family to survive (Interview with A. Gai, 27 March 2017).

In another part, the local customary leader explained that it is true that environmental damage has resulted in floods and landslides, but that is a reality in a society that has been difficult to solve until now. The working culture of peasants and with a deeply rooted socio-cultural system that is related to vital needs to sustain life and human civilization is not easy to divert the work of the Nuanaga people. $O g o$ is an important part of the sociocultural and economic system of agriculture which protects the forest as the most important resource in life, in addition to planting field maize and rice, and other secondary crops, farmers also plant cashew and candlenut trees which are an important part and the main producer besides coconut in the area. We are fully aware that overexploitation of forest resources has increased to forest damage, namely floods and landslides, as happened in February 2016 which damaged roads and bridges, community plantations, housing, and human settlements (Interview with Village Secretary Florintus Kajo, dated, 30 March 2017)

The impact of ogo as a cultural system of shifting cultivation, namely the occurrence of floods and landslides such as what happened in February 2026 which damaged residential housing, roads and bridges, community cultivation, and cashew plantation crops also suffered very severe damage. With the availability of natural resources in unequal quantity or quality, imbalance, excessive use, while development activities require increasing natural resources, therefore the risk of community activities as mentioned above has an impact on decreasing the quantity and quality of natural resources. and forests 
wherein the community continues to experience lags in their lives.

Therefore, the culture of ogo as a shifting cultivation system must be pushed slowly to be stopped, the community must be able to take advantage by developing creativity and other innovations, namely being able to shift to a pattern of economic activities, trade, crafts, carpentry skills, fisheries as fishermen and small businesses other medium enterprises (UKM), while maintaining and improving the system of care and cultivation of plantation crops with the best possible use to increase higher than usual income. The principle of environmental management must be based on the spirit of sustainability, prudence and the farming community must have the same values and spirit to maintain local wisdom so that the function of forest conservationists from generation to generation is maintained.

\section{Structural functionalism theory and environmental damage}

Natural resources, nature and humans, animals, and all living things on planet Earth have a very close relationship with one another. This interdependent interaction relationship is intended so that there is a balance of natural resources, humans, plants, animals, and the continuity of life from time to time and from generation to generation until this world ends or ends. Therefore, the interdependence relationship between each component is called functionalism, which means that one element or element is mutually attached to another if there is one element or element experiencing disfunction, disorder. then of course there will be new problems and will continue.

In the structural-functionalism perspective, the basic assumption is that each structure in a social system is functional towards the others. Conversely, if it is not functional, the structure will not exist or will disappear by itself. In the extreme adherents of this theory assume that all events and all structures are functional for a society (Ritzer, 1992). According to Lauer, this theory is based on seven assumptions, namely: (1) society must be analyzed as a complete unit consisting of interacting parts; (2) existing relationships can be one-way or reciprocal in nature; (3) the existing social system is dynamic; the existing adjustments do not need to greatly transform the system as a whole; (4) there has never been perfect integration in society, so that in society there will always be tensions and irregularities, but these tensions and deviations will be neutralized through the institutional process; (5) changes will take place gradually and slowly as a process of adaptation and adjustment; (6) change is the result of adjustment from outside, growing by differentiation and innovation; and (7) the system is integrated through having the same values (Zamroni, 1988).

Thinking about the system is a complex unit, consisting of various interrelationships and cannot be separated from the surrounding environment by certain limits. Organisms are clear examples of a system, as are molecules, buildings, planets, and galaxies. General thinking like this can also be applied to human society with various levels of complexity. At the macro level, the entire world community (humanity) can be imagined as a system. At the intermediate level (mezzo) the nation-state and regional political units or military alliances can be seen as a system. At the microlevel, local communities, associations, companies, families, or friends can be treated as a small system. Likewise, certain segments of society such as economic, political, and cultural aspects can also qualitatively be imagined as a system. Thus, in the hands of systems theorists such as Parsons (1902 1979), the thought of social systems finds its general form and universally applicable. Social change can be imagined as changes that occur within or include social systems. More precisely, there are differences between the state of a particular system over different periods.

Structural functionalism is one of the notions or perspectives in sociology that views society as a system consisting of parts that are interconnected with one another and one part that cannot function without any connection with the other. Then, changes that occur in one part will cause imbalance and in turn create changes in other parts. The development of functionalism is based on a model of the development of an organism system found in biology (Waters, Malcolm. 1994). The basic assumption of this theory is that all elements or elements of community life must be functional or functional so that society as a whole can carry out its functions properly, including natural humans and the environment at large.

To better understand these theoretical aspects, we can analyze agri-cultural activities, marketing of 
agricultural products, how to organize the management of agricultural activities, production and marketing of agricultural products (demand and supply). The food industry, the clothing industry, the aerospace industry. What if the agricultural production does not meet the maximum results, what about the marketing aspects and the price of the materials offered and/or marketed. The point is mutually functional from one another. What about the bureaucratic service system to the community if you experience obstacles or are disturbed, how are the results obtained, how will the public/consumer respond. According to the structural functionalism theory, agricultural activities from upstream to downstream should not cause congestion of one component against another, thus creating an imbalance or congestion (pathological).

Therefore, the emphasis on structural functionalism theory is that there is a balance in the use of natural environmental resources and their use by human beings, especially the farming community in Nuanaga village. Ogo, as an inseparable part of the life of the farming community in Nuanaga village, of course, cannot be avoided, especially in rural areas that only rely on their livelihoods from the dry land agricultural sector, but the use of forest resources if exploitation is carried out on a large scale every year will result in environmental impacts and humanitarian disasters, especially damage to floods, landslides and damage to residents' homes and other public facilities, roads, bridges and so on.

\section{Analysis of the theory of rational choice of ego and environmental damage}

Viewed from the perspective of rational choice theory, shifting cultivation of land is a rational choice, meaning that from the point of view of this theory it confirms that the choice of a person or group of individuals in their life activities as farmers with the development of shifting cultivation is a rational action that is profitable in fulfilling necessities of life.

Historically, rational choice theory has had a strong influence from the utilitarian theory of action which is the most influential theory in economics. Utilitarian theory even influences many other social choice theories, such as neoclassical economics, game theory, and public policy choice theory. According to Habermas, as quoted by Johnson (2008), rational choice theory expressly formulates assumptions, such as agents (actors) are seen as having a rule and are consistent with a set of preferences and choosing ways or strategies that can maximize utility for them.

From classical economists, there is an assumption that states that actors have "rational" characteristics. This assumption actually comes from Adam Smith's assumption about the operation of the economic system in society through the mechanism of "invisible hands" (the invisible hand). In Adam Smith's view, only this mechanism is capable of creating the fairest society. However, it should be noted that Smith was different from other neoclassical economists. In Adam Smith's view, only this mechanism is capable of creating the fairest society. However, it should be noted that Smith was different from other neoclassical economists.

The assumption of utilitarian rationality is the same as what we know in the development of social theory today. A rational person is considered to have a coherent set of preferences for the choices open to him. He ranks the various options based on the consideration of the extent to which these options meet his goals. He tends to make choices that satisfy his desires, instead of reducing his desires, and choices that are more likely to achieve (Rawls, 2006).

The above description shows that the assumptions used by rational choice theory and a number of other social science theories based on utilitarian philosophy have experienced "inherent defects". Humans are assumed to be rational beings who act "solely" based on optimizing the utility of the preferences (choices) they already have. The preference framework is relatively fixed. This assumption regarding human nature is an extraordinary simplification. Basically, all forms of human behavior, apart from reflecting on psychological conditions, are strongly influenced by cultural settings and environmental and social conditions in which the action takes place. Thus, the assumptions of rational choice theory negate social environmental factors, such as norms, values, and beliefs that develop in society, which in fact do not always lead people to act in self-interest. Individuals are thus assumed in rational choice theory to be under-socialized.

Rational choice theory like other microscopic sociological theories is centered on the actor as one 
of the key elements of the theory. Another element is resources. An actor in the theory of rational choice is assumed to have an intention/purpose (intentional) in every action. There is no action that is not purposeful. Other than that; actors are also assumed to always have a preference frame-work (choice framework) that is relatively fixed or stable. Choices made by actors based on that preference framework. In rational choice theory, individuals are seen as very rational, capable of doing their best to satisfy their desires. According to Molm (2005), rational choice theory adopts an atomist view, which focuses on individual preferences and choices as a basis for explaining social behavior, including the construction and utilization of institutions.

Each actor in taking action has different capital in the form of resources and also access to these resources. Resources are what actors want and want. This difference in control of natural resources has resulted in imbalances in the structure of the relationship with all the resulting consequences. Thus, differences in control of resources result in differences in power in the structure of relations between actors.

In carrying out their actions, actors or farmers first make a selection of the available (or possible) options by taking into account all aspects such as what objectives are their priorities, the resources they have and also the probability of success of their actions. An actor may choose not to pursue the most valuable goals because it may have insufficient resources, the likelihood of success is low, or it may jeopardize other goals it desires. Thus, actors or farmers are seen as always trying to maximize their profits by opening up ogo.

\section{ConClusion}

$O g o$ as a cultural system of shifting cultivation is an inseparable part of the life of the farming community in Nuanaga Village. Ogo as a system of agricultural work culture has been going on throughout the history of the life of the peasant community in Nuanaga who only rely on their economic life in this field. Ogo has a long history because, in connection with the expansion of agricultural land, it is also intended not only to plant rice, maize, and other crops, but also to plant cashew nut plantation and other longevity plants to improve the standard of living and welfare of his family.

$O g o$ as a cultural system of work of shifting cultivation continues over a long period of time, causing a reduction in forest area, massive logging, natural and environmental damage, floods, and landslides. $O g o$ as a system of work culture for field farmers only lasts for about three to four years and will move from place to place because in 3 to 4 years the soil nutrients are no longer wells and the commercial crops planted in the first year have grown higher. Even for cashew plants it can bear fruit and can be harvested. $O g o$ as a socio-cultural system of shifting cultivation is a rational choice for farmers to increase family income and welfare, even though floods and landslides often occur in highintensity rainy seasons.

\section{REFERENCES}

Allan, G. (1991) 'Qualitative Research', in G. Allan and C. Skinner (eds), Handbook for Research Students (London, Falmer Press). Allen, J. (1990) 'Does Feminism Need a Theory of 'the State"?', in S. Watson (ed.), Playing the State: Australian Feminist Interventions. London: Verso.

Bailey, Kenneth D. (1987). Methods of Social Research. Free Press: London. Bair, Forrest

E. and Walter Kaufmann, ed. Nineteenth Century Philosophy. New Jersey: Prentice Hall.

Creswell, John. (1994). Research Design: Qualitative and Quantitative Approach. Oslo: Sage Publications.

Coleman, James S. (1990). Foundation of Social

Theory. Cambridge: Belknap Press of Harvard University Press.

Heckarthorn, Douglas D. (2001). "Sociological Rational Choice." Dalam George Ritzer and Barry Smart (eds). Handbook of Social Theory. First Published. London, California, New Delhi: Sage Publications.

Johnson, Doyle Paul. (2008). Contemporary Sociological Theory: An Integrated MultiLevel Approach. Texas Tech University: Springer.

Molm, Linda. (2005a). "George Homans". Dalam George Ritzer (ed). Encyclopedia of Social Science. Vol I. Thousand Oak, London, New Delhi: Sage Publications. 
Molm, Linda. (2005b). "Rational Choice Theory". In George Ritzer (ed.). Encyclopedia of Social Theory. Vol I. Thousand Oaks, London, New Delhi: Sage Publications.

Parsons, Talcott. (1902). Social Systems and the Evlolutions of action Theory, New York Free Press.

Poloma, Margareth. (1997). Teori Sosiologi Kontemporer, Jakarta, Publisher Raja Grafindo Persada.

Ritzer, George. (1992). Contemporary Sociological Theory. New York: Alfreda Knopf.

Popoer, Karl. (1971). The Open Sociaty and its Enemies, Vol. 2 The High Tide of Prophecy; Hegel, Marx, and the aftermach, Prenceton, University Press.

Priyono, B. Herry. (2008). " Hunting for Economic Man.” In BASIS Magazine. No. 01-02. January to February. 57th years. Yogyakarta. Rawls, John. (2006). Justice Theory: Basics of Political Philosophy to Achieve Social Welfare in the State. Translation: Uzair Fauzan and Heru Prasetyo. Prints I. Yogyakarta: Student Library.

Republic of Indonesia Law No. 32 of 2009 concerning Environmental Protection and Management.

The 1945 Constitution of the Republic of Indonesia, Jakarta State Secretariat of the Republic of Indonesia

Waters, Malcolm. (1994). Modern Sociological Theory. London, California, New Delhi: Sage Publications.

Weber, Max. (1963). Theory and Social Economic Organization. New York: The Free Press. Zamroni. (1988). Introduction to Social Theory Development, Yogyakarta: Tiara Wacana. 